\title{
Linagliptin Increases Incretin Levels, Lowers Glucagon, and Improves Glycemic Control in Type 2 Diabetes Mellitus
}

Thomas Rauch • Ulrike Graefe-Mody • Carolyn F. Deacon • Arne Ring •

Jens J. Holst $\cdot$ Hans-Juergen Woerle $\cdot$ Klaus A. Dugi $\cdot$ Tim Heise

To view enhanced content go to www.diabetestherapy-open.com

Received: July 19, 2012 / Published online: September 18, 2012

(C) The Author(s) 2012. This article is published with open access at Springerlink.com

\section{ABSTRACT}

Introduction: Linagliptin is a xanthine-based dipeptidyl peptidase (DPP)-4 inhibitor that is now available in numerous countries worldwide for the treatment of type 2 diabetes mellitus (T2DM). The aim of this study was to evaluate further the mechanisms underlying the improvements in glycemic control observed with linagliptin. The effects of linagliptin on DPP-4, pharmacodynamic parameters, and

ClinicalTrials.gov Identifier: NCT00716092.

T. Rauch · U. Graefe-Mody · A. Ring · H.-J. Woerle K. A. Dugi

Boehringer Ingelheim, Ingelheim, Germany

C. F. Deacon · J. J. Holst

Department of Biomedical Sciences, Panum Institute, University of Copenhagen, Blegdamsvej, Copenhagen N, Denmark

T. Heise $(\square)$

Profil Institut für Stoffwechselforschung $\mathrm{GmbH}$, Hellersbergstr. 9, Neuss, Germany

e-mail: tim.heise@profil.com

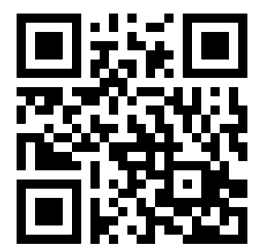

Enhanced content for this article is available on the journal web site: www.diabetestherapy-open.com glycemic control versus placebo were assessed in patients with inadequately controlled T2DM. Methods: Patients in this phase 2a, multicenter, randomized, double-blind, placebo-controlled study received placebo $(n=40)$ or linagliptin $5 \mathrm{mg}(n=40)$. Sitagliptin $100 \mathrm{mg}(n=41)$ once daily for 4 weeks was included for exploratory purposes. Primary endpoints for linagliptin versus placebo: change from baseline to day 28 in 24-h weighted mean glucose (WMG) and intact glucagon-like peptide (GLP)-1 area under the time-effect curve between 0 and $2 \mathrm{~h}\left(\right.$ AUEC $\left._{0-2 \mathrm{~h}}\right)$ following meal tolerance test on day 28 .

Results: Linagliptin increased intact GLP-1 AUEC $_{0-2 \mathrm{~h}}(+18.1 \mathrm{pmol} / \mathrm{h} / \mathrm{L})$ and lowered 24-h WMG (-1.1 mmol/L) versus placebo (both $P<0.0001)$ after 28 days. Intact glucosedependent insulinotropic polypeptide increased in line with GLP-1 $(+91.4 \mathrm{pmol} / \mathrm{h} / \mathrm{L}$ increase vs. placebo; $P<0.0001)$. Glycated hemoglobin $(-0.22 \% ; \quad P=0.0021)$, fasting plasma glucose $(-0.6 \mathrm{mmol} / \mathrm{L} ; P=0.0283)$, and glucose $\left(\right.$ AUEC $\left._{0-3 \mathrm{~h}}\right)(-5.9 \mathrm{mmol} / \mathrm{h} / \mathrm{L} ; P<0.0001)$ improved significantly with linagliptin versus placebo. Most adverse events were mild; hypoglycemia or serious adverse events were not reported. Sustained DPP-4 inhibition 
( $\geq 80 \%$ ) throughout the treatment period was accompanied by significant reductions in glucagon starting at day 1 of linagliptin administration.

Conclusion: Linagliptin was well tolerated and effectively inhibited plasma DPP-4 activity in patients with T2DM, producing immediate improvements in incretin levels, glucagon suppression, and glycemic control that were maintained throughout the study period.

Keywords: Dipeptidyl peptidase-4 inhibitors; Glucagon; Glucagon-like peptide-1; Glycemic control; Linagliptin; Type 2 diabetes mellitus

\section{INTRODUCTION}

Dipeptidyl peptidase (DPP)-4 inhibitors are oral antidiabetic agents that act by inhibiting the degradation of the gastrointestinal incretin hormones, glucagon-like peptide (GLP)-1 and glucose-dependent insulinotropic polypeptide (GIP), by the DPP-4 enzyme [1, 2]. The resulting increase in availability of these hormones stimulates glucose-dependent insulin release from pancreatic beta cells, while reducing glucagon output from pancreatic alpha cells [3].

Although there is no consensus on the best choice of antihyperglycemic agent for patients in whom metformin fails to maintain glycemic control, it has been suggested that the addition of a DPP-4 inhibitor may be appropriate, as these compounds seem to have a similar effect on glycated hemoglobin $\left(\mathrm{HbA}_{1 \mathrm{c}}\right)$ compared with sulfonylureas or thiazolidinediones, but without the risk of hypoglycemia or weight gain [4].

Linagliptin is a xanthine-based DPP-4 inhibitor that is now available in numerous countries worldwide for the treatment of type 2 diabetes mellitus (T2DM). Like most DPP-4 inhibitors, the pharmacological features of linagliptin permit once daily dosing, without the need for dose titration $[5,6]$. However, unlike other DPP-4 inhibitors, the excretion of linagliptin is largely via the bile and gut and, therefore, dose adjustment is not required in patients with declining renal function $[7,8]$.

Several clinical trials have demonstrated that linagliptin elicits reductions in $\mathrm{HbA}_{1 \mathrm{c}}$, fasting plasma glucose (FPG), and postprandial glucose (PPG) in patients with T2DM [6, 9-13].

The aim of the present study was to explore further the mechanisms underlying the improvements in glycemic control observed with linagliptin.

\section{MATERIALS AND METHODS}

\section{Study Population}

Patients aged between 18 and 80 years, with a body mass index of $40 \mathrm{~kg} / \mathrm{m}^{2}$ or less at screening, who were either treatment naive or had previously received monotherapy with oral antidiabetic agents and whose $\mathrm{HbA}_{1 \mathrm{c}}$ level was between $6.5 \%(\geq 47.4 \mathrm{mmol} / \mathrm{mol})$ and $10.0 \%$ $(\leq 85.8 \mathrm{mmol} / \mathrm{mol})$ were eligible.

The main exclusion criteria included myocardial infarction, stroke, or transient ischemic attack within 6 months before enrollment; impaired hepatic function; renal insufficiency; hypersensitivity or allergy to linagliptin, sitagliptin, or excipients; or treatment with rosiglitazone, pioglitazone, GLP-1 analogs, insulin, DPP-4 inhibitors, or anti-obesity drugs during the previous 3 months.

An independent ethics committee (Ärztekammer Nordrhein, Düsseldorf, Germany) approved the study, which was conducted according to the Declaration of Helsinki and the International Conference on Harmonisation 
harmonised tripartite guideline for good clinical practice. All patients gave written, informed consent to participate.

\section{Study Design}

This phase $2 \mathrm{a}$, multicenter, randomized, doubleblind, double-dummy, placebo-controlled, parallel-group study compared oral linagliptin (5 mg once daily) with placebo. While a sitagliptin arm (100 mg orally once daily) was included as a "positive control", the study was not statistically powered to compare the linagliptin and sitagliptin arms.

Patients already taking one oral antidiabetic medication underwent a 2-week washout. All patients underwent a 2-week, open-label, placebo run-in, followed by a 4-week treatment period with linagliptin, sitagliptin, or placebo. Post-treatment follow-up lasted 2 weeks.

Patients were randomly assigned using an interactive voice response system, stratified by $\mathrm{HbA}_{1 \mathrm{c}}$ at the beginning of the placebo run-in [ $<8.5 \%$ vs. $\geq 8.5 \%$ ( $<69.4$ vs. $\geq 69.4 \mathrm{mmol} / \mathrm{mol}$ )] and previous use of antidiabetic drugs.

Sitagliptin was over-encapsulated to maintain blinding of treatment allocation.

\section{Study Assessments}

Baseline measurements were made on day -1 (the day before randomization), and the study assessments [including meal tolerance test (MTT)] were performed on days 1, 28, 29, and 30. Repeated blood samples were taken to obtain blood glucose and hormone measurements, as described in detail later. Longer-term markers of blood glucose control were evaluated on days $-1,15,28$, and 42 .

The MTT consisted of two nutrition bars (which, together, provided $300 \mathrm{kCal}$, and contained $13 \mathrm{~g}$ protein, $40 \mathrm{~g}$ carbohydrate, and $10 \mathrm{~g}$ fat) and a high energy, high protein drink (which provided $300 \mathrm{kCal}$, and contained $16 \mathrm{~g}$ protein, $90 \mathrm{~g}$ carbohydrate, and $6 \mathrm{~g}$ fat). Markers determined after each MTT included plasma glucose, intact GLP-1, intact GIP, glucagon, insulin, and C-peptide levels. Longer-term markers of glycemic control included $\mathrm{HbA}_{1 \mathrm{c}}$, fructosamine, and 1,5-anhydroglucitol.

Plasma glucose was measured electrochemically with a biosensor-based assay (Super GL, Hitado, Möhnesee-Delecke, Germany). Intact GLP-1 was measured by a fluorescence-based enzyme-linked immunosorbent assay, using a Linco research system (Linco Research Inc., St Charles, MO, USA) instrument. Plasma DPP-4 levels were determined using a semiquantitative enzyme activity assay with fluorescence detection, which has been described previously [14].

Levels of intact GIP and $\mathrm{HbA}_{1 \mathrm{c}}$ were measured as described previously [15-17]. International Federation of Clinical Chemistry values for $\mathrm{HbA}_{1 \mathrm{c}}$ were converted from percentages to $\mathrm{mmol} / \mathrm{mol}$. Glucagon, insulin, and C-peptide levels were analyzed using specific immunoassays. Levels of fructosamine and 1,5-anhydroglucitol were measured using specific enzymatic assays.

Throughout the study, safety was assessed based on adverse event frequencies and severities, vital signs, 12-lead electrocardiogram, physical examination, and laboratory tests.

\section{Endpoints}

The primary assessments, after 28 days of treatment, were change from baseline in weighted mean glucose (WMG), and change from baseline in the area under the time-effect curve between 0 and $2 \mathrm{~h}\left(\mathrm{AUEC}_{0-2 \mathrm{~h}}\right.$ ) for GLP-1 following a MTT. The secondary assessments were change in FPG from baseline to day 28 , and 
change in plasma glucose $\left(\mathrm{AUEC}_{0-3 \mathrm{~h}}\right.$ ) following a MTT from baseline to day 28.

Additional pharmacodynamic assessments included levels of intact GIP, glucagon, insulin, C-peptide, 2-h PPG, and inhibition of plasma DPP-4.

Areas under the curves were determined with the trapezoidal rule. For WMG, the area under the glucose concentration-time curve over $24 \mathrm{~h}$ was divided by 24 .

\section{Statistical Analyses}

The primary, secondary, and other quantitative pharmacodynamic endpoints were evaluated using an analysis of covariance model with treatment as the fixed effect. For each endpoint, the corresponding baseline value (obtained at day -1) was included in the model as a linear covariate. The variables, previous use of antidiabetic agents, and $\mathrm{HbA}_{1 \mathrm{c}}[<8.5 \%$ vs. $\geq 8.5 \%$ ( $<69.4$ vs. $\geq 69.4 \mathrm{mmol} / \mathrm{mol})]$ at baseline, were included in the model, as the randomization was stratified using these parameters. Testing of superiority of linagliptin versus placebo for the primary and secondary endpoints after 4 weeks of treatment was performed (one-sided at the 0.025 level). The Wilcoxon-Mann-Whitney test was used for treatment comparisons of DPP-4 inhibition, and Hodges-Lehmann estimates for the median differences and their confidence intervals (CIs).

For sample size estimation, the placeboadjusted change from baseline in WMG was assumed to be $-17.2 \mathrm{mg} / \mathrm{dL} \quad(0.95 \mathrm{mmol} / \mathrm{L})$, with a SD of $22.6 \mathrm{mg} / \mathrm{dL}(1.25 \mathrm{mmol} / \mathrm{L})$ (based on a study by Brazg et al. [18]). Lower variability was assumed for the other primary endpoint, GLP-1 AUEC $_{0-2 \mathrm{~h}}$. Based on these assumptions, 38 completers per treatment arm were needed to achieve a power of $90 \%$ for the change in
WMG, whereas the power was greater than $98 \%$ for GLP-1 AUEC $0-2 \mathrm{~h}$.

A per protocol set of patients was created for analyses of the primary and secondary endpoints to compare linagliptin with placebo. In addition, an exploratory analysis was performed using the data obtained from subjects receiving sitagliptin treatment. However, the trial was not designed or sufficiently powered to compare the efficacy or tolerability of linagliptin with sitagliptin.

\section{RESULTS}

\section{Demographic and Baseline Characteristics}

Demographic and baseline characteristics were similar across the patient groups. The mean (SD) baseline values for $\mathrm{HbA}_{1 \mathrm{c}}$ were $7.3 \%(0.53 \%)$, and for FPG were 9.25 (1.53) mmol/L. Diabetes medications used previously (67.8\% of patients) were metformin (55.4\%), sulfonylureas (9.1\%), and glinides (3.3\%). A total of 121 patients was randomly assigned (40 to placebo, 40 to linagliptin, and 41 to sitagliptin). Three patients $(2.5 \%)$ withdrew from the study prematurely: two patients in the placebo arm who experienced hyperglycemia, and one patient in the linagliptin group for whom there was difficulty in obtaining blood samples. One subject in the placebo group had a protocol violation that was considered to be important during blinded review (incorrect timing of administration of trial medication). The analysis of secondary, but not the primary, endpoints excluded this patient and was performed using data obtained from the 117 patients who completed the study without relevant protocol violations. Data on demographics, baseline characteristics, and safety were derived from the complete patient set $(n=121)$. 


\section{Primary and Secondary Endpoints}

After 4 weeks of treatment, linagliptin elicited decreases in 24-h WMG and increases in GLP-1 AUEC $_{0-2 \mathrm{~h}}$ (Table 1). These changes were significantly larger than those seen with placebo $(P<0.0001$ for all comparisons $)$. Likewise, linagliptin achieved significant placebo-corrected changes from baseline for FPG and for glucose AUEC $_{0-3 \mathrm{~h}}$.

\section{Inhibition of DPP-4}

Median DPP-4 inhibition achieved by linagliptin treatment at trough was $79.8 \%$ at day 2 ( $24 \mathrm{~h}$ after the first dose). DPP-4 inhibition by linagliptin was then sustained at $80 \%$ or greater throughout the treatment period. On day 28, median DPP-4 inhibition at trough was $82.2 \%$ for linagliptin and $70.3 \%$ for sitagliptin (estimate of median difference: $12.6 \% ; 95 \%$ CI $9.5 \%$ to $15.7 \% ; P<0.0001)$. Two weeks after the last dose of linagliptin to plasma DPP-4 was still inhibited by approximately $17 \%$.

\section{Effects on Incretins and Other Peptide Hormones}

Linagliptin therapy increased placebo-corrected intact GIP AUEC $\mathrm{C}_{0-2 \mathrm{~h}}$ by approximately 1.5 -fold on day 1 (from a baseline value of $129.9 \pm 9.0 \mathrm{pmol} / \mathrm{h}$ ) with approximately a two-fold increase observed on day 28 (Table 2). Data for intact GLP-1 AUEC $_{0-2 \mathrm{~h}}$ on day 1 were in line with these data, showing increases of similar magnitude on days 1 and 28 (Tables 1 and 2). Placebo-corrected levels of glucagon decreased significantly on days 1 and 28 with linagliptin. For insulin and C-peptide, changes from baseline were not significant.

Following a MTT on day 28, mean plasma concentrations of intact GLP-1 increased in the linagliptin-treated group compared with placebo, at all time points evaluated (Fig. 1). In line with these changes, mean plasma glucagon levels were reduced in the linagliptin-treated group versus placebo.

\section{Effects on Plasma Glucose Parameters}

The placebo-adjusted changes from baseline of plasma glucose parameters following linagliptin therapy were statistically significant on days 1 and 28, including 2-h PPG, peak glucose, glucose $\mathrm{AUEC}_{0-3 \mathrm{~h}}$, and 24-h WMG (Tables 1 and 2). For FPG, the placebo-adjusted change from baseline was not significant on day 1 but reached statistical significance on day 28 .

Placebo-adjusted means for $\mathrm{HbA}_{1 \mathrm{c}}$ showed a nonsignificant reduction on day 15 and significant reductions on days 28 (Table 2) and $42(-0.28 \% ; 95 \% \mathrm{CI}-0.42$ to -0.13 ; $P=0.0003)$. Fructosamine showed a significant reduction from baseline on day 28 , but not on day 15 of treatment (Table 2) or at 2 weeks posttreatment (day 42$)(-5.1 \mu \mathrm{mol} / \mathrm{L} ; 95 \% \mathrm{CI}-16.8$ to $6.5 ; P=0.3848)$. There were significant increases from baseline in 1,5-anhydroglucitol levels on days 15 and 28 (Table 2), but at 2 weeks post-treatment (day 42) the increase was not statistically significant $(0.8 \mu \mathrm{g} / \mathrm{mL} ; 95 \%$ CI -1.0 to $2.6 ; P=0.3634$ ).

The 24-h glucose profile, evaluated on day 28 , showed that linagliptin was associated with lower mean plasma glucose concentrations at all time points, compared with placebo (Fig. 1).

Results obtained on days 29/30 were essentially similar; therefore, only data from day 28 are presented.

\section{Exploratory Analyses: Linagliptin versus Sitagliptin}

Additional exploratory sensitivity analyses, including all three study treatments, compared 
Table 1 Primary (changes in WMG and GLP-1 AUEC ${ }_{0-2 h}$ ) and secondary (changes in FPG and glucose AUEC $0-3 \mathrm{~h}$ ) endpoints after 28 days of treatment with linagliptin $(5 \mathrm{mg}$ once daily) or placebo

\begin{tabular}{|c|c|c|}
\hline & Placebo & Linagliptin \\
\hline \multicolumn{3}{|l|}{ Primary endpoints } \\
\hline \multicolumn{3}{|l|}{ 24h-WMG (mmol/L) } \\
\hline Baseline mean (SE) & $10.6(0.3)$ & $10.5(0.4)$ \\
\hline Adjusted mean change from baseline (SE) & $0.01(0.2)$ & $-1.1(0.2)$ \\
\hline Comparison vs. placebo: adjusted mean change ( $95 \% \mathrm{CI}$ ) & - & $-1.1(-1.6,-0.7)$ \\
\hline$P$-value & - & $<0.0001$ \\
\hline \multicolumn{3}{|l|}{ Intact GLP-1 AUEC $_{0-2 \mathrm{~h}}(\mathrm{pmol} / \mathrm{h} / \mathrm{L})$} \\
\hline Baseline mean (SE) & $15.0(1.9)$ & $17.4(1.8)$ \\
\hline Adjusted mean change from baseline (SE) & $0.4(2.1)$ & $18.5(2.1)$ \\
\hline Comparison vs. placebo: adjusted mean change (95\% CI) & - & $18.1(12.4,23.9)$ \\
\hline$P$-value & - & $<0.0001$ \\
\hline \multicolumn{3}{|l|}{ Secondary endpoints } \\
\hline \multicolumn{3}{|l|}{$\mathrm{FPG} \mathrm{mmol/h/L}$} \\
\hline Baseline mean (SE) & $9.4(0.2)$ & $9.2(0.2)$ \\
\hline Adjusted mean change from baseline (SE) & $-0.01(0.2)$ & $-0.6(0.2)$ \\
\hline Comparison vs. placebo: adjusted mean change ( $95 \% \mathrm{CI})$ & - & $-0.6(-1.1,-0.1)$ \\
\hline$P$-value & - & 0.0283 \\
\hline \multicolumn{3}{|l|}{ Glucose AUEC $_{0-3 \mathrm{~h}}(\mathrm{mmol} / \mathrm{h} / \mathrm{L})$} \\
\hline Baseline mean (SE) & $40.1(1.2)$ & $40.4(1.3)$ \\
\hline Adjusted mean change from baseline (SE) & $0.4(0.8)$ & $-5.5(0.8)$ \\
\hline Comparison vs. placebo: adjusted mean change ( $95 \% \mathrm{CI})$ & - & $-5.9(-8.2,-3.7)$ \\
\hline$P$-value & - & $<0.0001$ \\
\hline
\end{tabular}

$A U E C$ area under the time-effect curve, $C I$ confidence interval, FPG fasting plasma glucose, GLP-1 glucagon-like peptide-1, $S E$ standard error, $W M G$ weighted mean glucose

the effects of linagliptin $(n=39)$ and sitagliptin $(n=40)$ on the primary and secondary endpoints, between baseline and day 28. The reduction of WMG was numerically greater with sitagliptin compared with linagliptin on day 28 (difference of $0.3 \pm 0.2 \mathrm{mmol} / \mathrm{L} ; 95 \% \mathrm{CI}$ -0.1 to $0.8 ; P=0.1274)$. The corresponding increase in intact GLP-1 AUEC $_{0-2 h}$ was numerically greater with linagliptin than with sitagliptin (difference of $2.8 \pm 2.7 \mathrm{pmol} / \mathrm{h} / \mathrm{L}$; 95\% CI -2.7 to $8.2 ; P=0.3130$ ). For FPG and glucose $\mathrm{AUEC}_{0-3 \mathrm{~h}}$, the reductions were numerically greater for sitagliptin versus linagliptin, with differences of $0.3 \pm 0.2 \mathrm{mmol} /$ L $(95 \%$ CI -0.2 to $0.8 ; \quad P=0.2281)$ and $1.3 \pm 1.0 \mathrm{mmol} / \mathrm{h} / \mathrm{L} \quad(95 \% \quad \mathrm{CI}-0.8$ to 3.3 ; 
Table 2 Exploratory endpoints: baseline values (day -1$)$ and adjusted mean changes from baseline on days 1, 15, and 28 (where data available)

\begin{tabular}{|c|c|c|c|c|c|c|}
\hline & \multicolumn{2}{|l|}{ Day 1} & \multicolumn{2}{|l|}{ Day 15} & \multicolumn{2}{|l|}{ Day 28} \\
\hline & Placebo & Linagliptin & Placebo & Linagliptin & Placebo & Linagliptin \\
\hline \multicolumn{7}{|l|}{ Intact GLP-1 $\mathrm{AUEC}_{0-2 \mathrm{~h}}(\mathrm{pmol} / \mathrm{h} / \mathrm{L})$} \\
\hline Baseline (SE) & $14.6(1.9)$ & $17.4(1.8)$ & - & - & & \\
\hline Mean change from baseline & 0.8 & 11.3 & - & - & \multicolumn{2}{|c|}{ See Table 1} \\
\hline Comparison vs. placebo (95\% CI) & - & $10.5(6.5,14.6)$ & - & - & & \\
\hline$P$-value & - & $<0.0001$ & - & - & & \\
\hline \multicolumn{7}{|l|}{ Intact GIP AUEC ${ }_{0-2 h}(\mathrm{pmol} / \mathrm{h} / \mathrm{L})$} \\
\hline Baseline (SE) & $105.2(7.2)$ & $129.9(9.0)$ & - & - & $105.2(7.2)$ & $129.9(9.0)$ \\
\hline Mean change from baseline & 28.7 & 69.5 & - & - & 15.2 & 106.6 \\
\hline Comparison vs. placebo $(95 \% \mathrm{CI})$ & - & $40.7(13.9,67.5)$ & - & - & - & $91.4(67.0,115.8)$ \\
\hline$P$-value & - & 0.003 & - & - & - & $<0.0001$ \\
\hline \multicolumn{7}{|l|}{ Total GIP AUEC ${ }_{0-2 h}(\mathrm{pmol} / \mathrm{h} / \mathrm{L})$} \\
\hline Baseline (SE) & $239.6(18.1)$ & $301.4(21.2)$ & - & - & $239.6(18.1)$ & $301.4(21.2)$ \\
\hline Mean change from baseline & 50.5 & -82.8 & - & - & 12.6 & -94.0 \\
\hline Comparison vs. placebo $(95 \% \mathrm{CI})$ & - & $-133.3(-186.6,-80.0)$ & - & - & - & $-106.7(-147.9,-65.4)$ \\
\hline$P$-value & - & $<0.0001$ & - & - & - & $<0.0001$ \\
\hline \multicolumn{7}{|l|}{ Insulin $\operatorname{AUEC}_{0-2 \mathrm{~h}}(\mathrm{mU} / \mathrm{h} / \mathrm{L})$} \\
\hline Baseline (SE) & $87.6(6.9)$ & $100.6(8.5)$ & - & - & $87.6(6.9)$ & $102.4(8.2)$ \\
\hline Mean change from baseline & 19.7 & 15.5 & - & - & 7.2 & -0.7 \\
\hline Comparison vs. placebo $(95 \%$ CI) & - & $-4.3(-19.1,10.6)$ & - & - & - & $-8.0(-22.3,6.4)$ \\
\hline$P$-value & - & 0.57 & - & - & - & 0.27 \\
\hline \multicolumn{7}{|l|}{ C-peptide $\mathrm{AUEC}_{0-2 \mathrm{~h}}(\mathrm{pmol} / \mathrm{h} / \mathrm{L})$} \\
\hline Baseline (SE) & $4,515.0(212.7)$ & $5,081.0(232.4)$ & - & - & $4,515.0(212.7)$ & $5,161.4(238.5)$ \\
\hline Mean change from baseline & 716.7 & 394.4 & - & - & -121.6 & -146.5 \\
\hline Comparison vs. placebo $(95 \% \mathrm{CI})$ & - & $-322.3(-684.7,40.1)$ & - & - & - & $-24.8(-445.7,396.0)$ \\
\hline$P$-value & - & 0.08 & - & - & - & 0.91 \\
\hline \multicolumn{7}{|l|}{ Glucagon $\operatorname{AUEC}_{0-2 \mathrm{~h}}(\mathrm{pg} / \mathrm{h} / \mathrm{mL})$} \\
\hline Baseline (SE) & $183.0(11.5)$ & $182.1(6.6)$ & - & - & $183.0(11.5)$ & $182.1(6.6)$ \\
\hline Mean change from baseline & 17.3 & -6.1 & - & - & 1.3 & -17.4 \\
\hline Comparison vs. placebo (95\% CI) & - & $-23.4(-36.8,-10.1)$ & - & - & - & $-18.7(-37.0,-0.4)$ \\
\hline$P$-value & - & 0.0008 & - & - & - & 0.0452 \\
\hline \multicolumn{7}{|l|}{ 2-h PPG (mmol/L) } \\
\hline Baseline (SE) & $14.6(0.6)$ & $14.8(0.6)$ & - & - & $14.6(0.6)$ & $14.8(0.6)$ \\
\hline Mean change from baseline & -0.2 & -1.3 & - & - & 0.1 & -2.3 \\
\hline Comparison vs. placebo $(95 \% \mathrm{CI})$ & - & $-1.1(-1.9,-0.3)$ & - & - & - & $-2.4(-3.5,-1.3)$ \\
\hline$P$-value & - & 0.009 & - & - & - & $<0.0001$ \\
\hline \multicolumn{7}{|l|}{ Peak glucose $(\mathrm{mmol} / \mathrm{L})$} \\
\hline Baseline (SE) & $15.8(0.5)$ & $15.9(0.5)$ & - & - & $15.8(0.5)$ & $15.9(0.5)$ \\
\hline Mean change from baseline & 0.2 & -1.5 & - & - & 0.04 & -2.2 \\
\hline Comparison vs. placebo $(95 \% \mathrm{CI})$ & - & $-1.7(-2.4,1.0)$ & - & - & - & $-2.2(-3.2,1.3)$ \\
\hline$P$-value & - & $<0.0001$ & - & - & - & $<0.0001$ \\
\hline
\end{tabular}


Table 2 continued

\begin{tabular}{|c|c|c|c|c|c|c|}
\hline & \multicolumn{2}{|l|}{ Day 1} & \multicolumn{2}{|l|}{ Day 15} & \multicolumn{2}{|l|}{ Day 28} \\
\hline & Placebo & Linagliptin & Placebo & Linagliptin & Placebo & Linagliptin \\
\hline \multicolumn{7}{|l|}{$\mathrm{FPG}^{*}(\mathrm{mmol} / \mathrm{L})$} \\
\hline Baseline (SE) & $9.5(0.2)$ & $9.2(0.2)$ & $9.5(0.2)$ & $9.2(0.2)$ & & \\
\hline Mean change from baseline & 0.09 & 0.03 & 0.2 & -0.5 & \multicolumn{2}{|c|}{ See Table 1} \\
\hline Comparison vs. placebo $(95 \% \mathrm{CI})$ & - & $-0.1(-0.6,0.4)$ & - & $-0.6(-1.1,-0.2)$ & & \\
\hline$P$-value & - & 0.7952 & - & 0.01 & & \\
\hline \multicolumn{7}{|l|}{ Glucose $_{\mathrm{AUEC}_{0-3 \mathrm{~h}}}(\mathrm{mmol} / \mathrm{h} / \mathrm{L})$} \\
\hline Baseline (SE) & $40.2(1.3)$ & $40.4(1.4)$ & - & - & & \\
\hline Mean change from baseline & 0.3 & -3.0 & - & - & \multicolumn{2}{|c|}{ See Table 1} \\
\hline Comparison vs. placebo $(95 \% \mathrm{CI})$ & - & $-3.3(-4.8,-1.7)$ & - & - & & \\
\hline$P$-value & - & 0.0001 & - & - & & \\
\hline \multicolumn{7}{|l|}{ 24-h WMG (mmol/L) } \\
\hline Baseline (SE) & $10.6(0.3)$ & $10.5(0.4)$ & - & - & & \\
\hline Mean change from baseline & 0.04 & -0.5 & - & - & \multicolumn{2}{|c|}{ See Table 1} \\
\hline Comparison vs. placebo $(95 \% \mathrm{CI})$ & - & $-0.5(-0.7,-0.3)$ & - & - & & \\
\hline$P$-value & - & $<0.0001$ & - & - & & \\
\hline \multicolumn{7}{|l|}{$\mathrm{HbA}_{\mathrm{lc}}(\%)$} \\
\hline Baseline (SE) & - & - & $7.42(0.1)$ & $7.31(0.1)$ & $7.42(0.1)$ & $7.31(0.1)$ \\
\hline Mean change from baseline & - & - & -0.10 & -0.15 & -0.06 & -0.27 \\
\hline Comparison vs. placebo $(95 \% \mathrm{CI})$ & - & - & - & $-0.05(-0.14,0.05)$ & - & $-0.22(-0.35,-0.08)$ \\
\hline$P$-value & - & - & - & 0.31 & - & 0.002 \\
\hline \multicolumn{7}{|l|}{$\mathrm{HbA}_{\mathrm{lc}}, \mathrm{mmol} / \mathrm{mol}$, IFCC } \\
\hline Baseline (SE) & - & - & $57.6(1.1)$ & $56.4(1.1)$ & $57.6(1.1)$ & $56.4(1.1)$ \\
\hline Mean change from baseline & - & - & -1.1 & -1.6 & -0.7 & -3.0 \\
\hline Comparison vs. placebo $(95 \% \mathrm{CI})$ & - & - & - & $-0.5(-1.5,0.5)$ & - & $-2.4(-3.8,-0.9)$ \\
\hline$P$-value & - & - & - & 0.31 & - & 0.002 \\
\hline \multicolumn{7}{|l|}{ Fructosamine $(\mu \mathrm{mol} / \mathrm{L})$} \\
\hline Baseline (SE) & - & - & $257.2(6.4)$ & $255.1(5.4)$ & $257.6(6.2)$ & $257.6(6.1)$ \\
\hline Mean change from baseline & - & - & 17.0 & 9.0 & 2.9 & -6.1 \\
\hline Comparison vs. placebo $(95 \% \mathrm{CI})$ & - & - & - & $-7.9(-17.6,1.8)$ & - & $-9.0(-17.9,-0.2)$ \\
\hline$P$-value & - & - & - & 0.1069 & - & 0.0446 \\
\hline \multicolumn{7}{|l|}{ 1,5-Anhydroglucitol $(\mu \mathrm{g} / \mathrm{mL})$} \\
\hline Baseline (SE) & - & - & $9.3(1.0)$ & $10.2(1.1)$ & $9.3(1.0)$ & $9.9(1.0)$ \\
\hline Mean change from baseline & - & - & -0.5 & 0.8 & -0.8 & 1.0 \\
\hline Comparison vs. placebo $(95 \% \mathrm{CI})$ & - & - & - & $1.3(0.8,1.8)$ & - & $1.8(1.0,2.5)$ \\
\hline$P$-value & - & - & - & $<0.0001$ & - & $<0.0001$ \\
\hline
\end{tabular}

Data shown are adjusted mean change from baseline

${ }^{*}$ FPG measured on day 2

- no data available

$A U E C$ area under the time-effect curve, $C I$ confidence interval, $F P G$ fasting plasma glucose, GIP glucose-dependent insulinotropic polypeptide, GLP-1 glucagon-like peptide-1, $H b A_{l c}$ glycated hemoglobin, IFCC international federation of clinical chemistry, $P P G$ postprandial glucose, $S E$ standard error, $W M G$ weighted mean glucose 
a
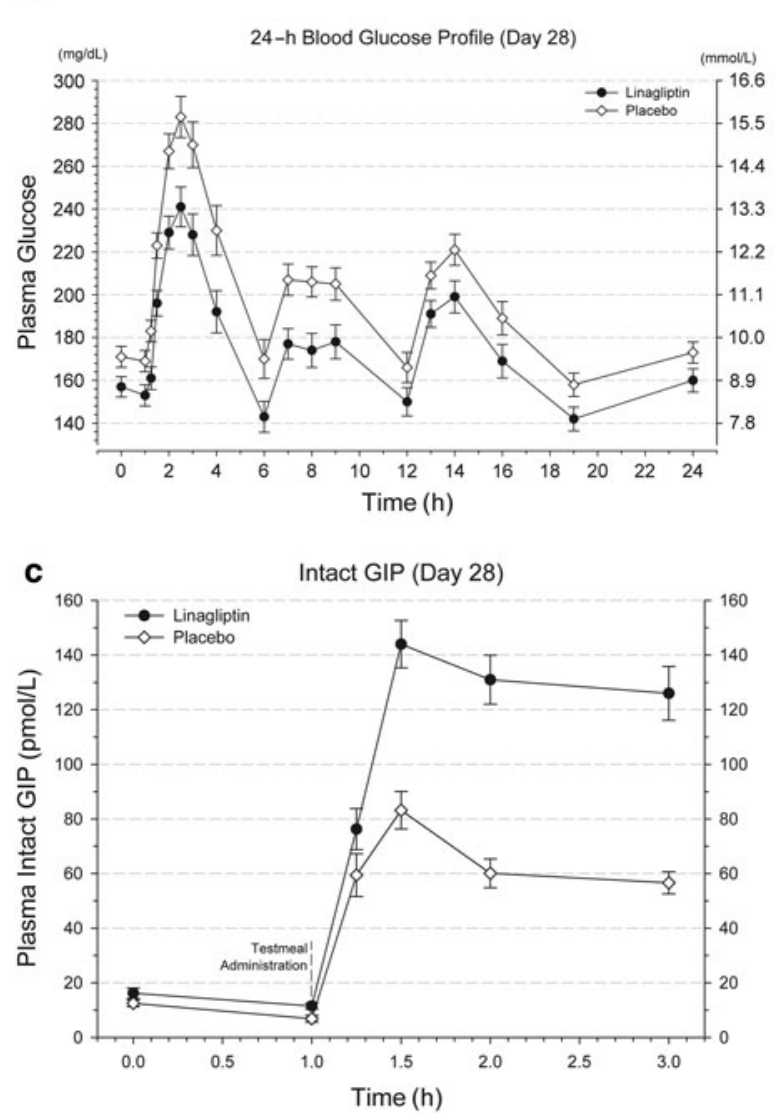

Fig. 1 24-h profile of mean plasma glucose (a), changes in intact GLP-1 (b), intact GIP (c), and glucagon over $2.5 \mathrm{~h}$ following a meal tolerance test (d), for subjects allocated to the linagliptin or placebo arms (day 28). Data are shown as

$P=0.2230)$, respectively. None of the observed differences between linagliptin and sitagliptin, for primary and secondary endpoints, were statistically significant.

\section{Safety and Tolerability}

The safety analysis comprised 121 patients who had received at least one dose of trial medication. Forty-three patients (35.5\%) experienced at least one adverse event during the study (Table 3). However, most adverse events were mild and there were no severe or serious adverse events; no adverse events led to
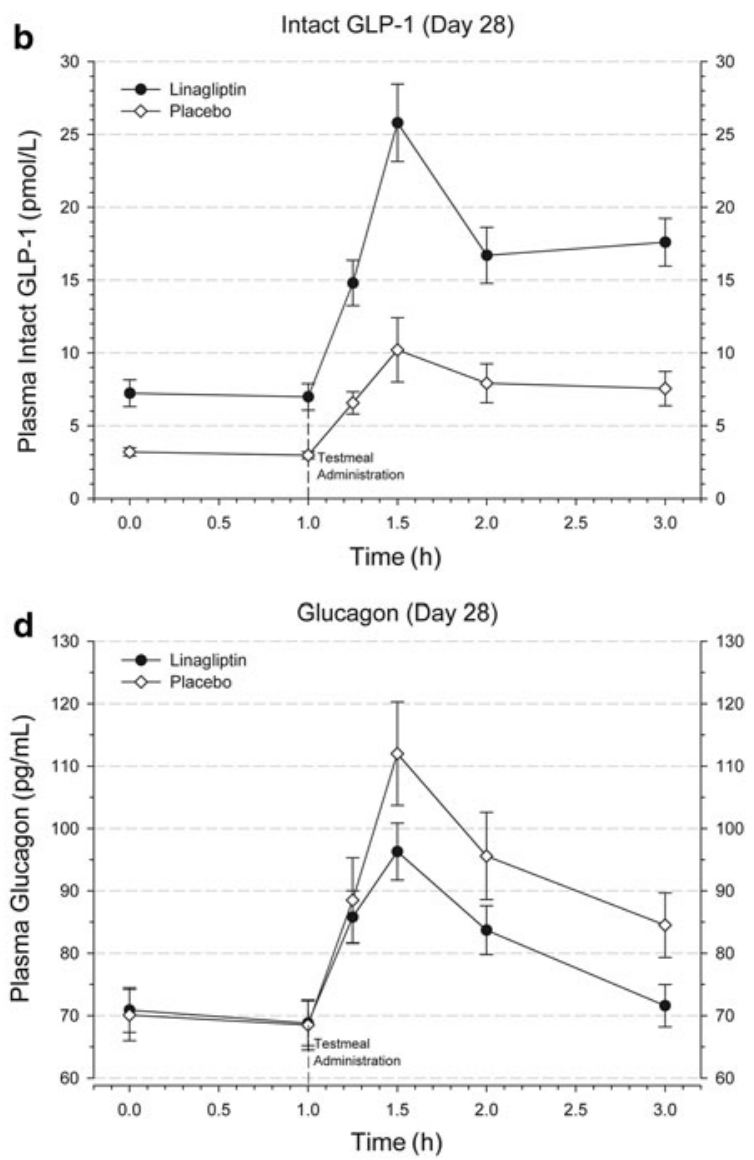

mean \pm standard error. Time point 0 , shown at the start of the weighted mean glucose interval, corresponds to approximately 8:00 a.m. GIP glucose-dependent insulinotropic polypeptide, GLP glucagon-like peptide

treatment discontinuation. During the washout phase, one patient experienced two severe adverse events that were not considered to be treatment related (aggravated migraine and a panic attack that required hospitalization). Headache, back pain, and nasopharyngitis were the most frequently reported adverse events. Drug-related adverse events occurred in one patient $(2.5 \%)$ in the placebo group (upper abdominal pain), two patients (5.0\%) in the linagliptin-treated group (headache and hyperhydrosis), and five patients (12.2\%) in the sitagliptin-treated group [headache (two patients), hot flush, abdominal distension, 
Table 3 Summary of adverse events that were reported in two or more patients of any treatment group (in order of frequency)

\begin{tabular}{llcc}
\hline & \multicolumn{1}{c}{$\boldsymbol{n}(\%)$} & & Sitagliptin \\
\cline { 2 - 4 } & Placebo & Linagliptin & $41(100)$ \\
Number of patients & $40(100)$ & $40(100)$ & $18(43.9)$ \\
Total with adverse events & $13(32.5)$ & $12(30.0)$ & $5(12.2)$ \\
Headache & $3(7.5)$ & $4(10.0)$ & $1(2.4)$ \\
Back pain & $2(5.0)$ & $3(7.5)$ & $2(4.9)$ \\
Nasopharyngitis & $1(2.5)$ & $2(5.0)$ & $0(0.0)$ \\
Epistaxis & $0(0.0)$ & $2(5.0)$ & $0(0.0)$ \\
Arthralgia & $0(0.0)$ & $2(5.0)$ &
\end{tabular}

rhinorrhea, and dry mouth]. Hypoglycemia was not reported in any treatment group. No clinically relevant changes in vital signs were observed.

\section{DISCUSSION}

This study provides the most detailed comparison to date of the acute and longerterm effects of linagliptin on glycemic control in patients with insufficiently controlled T2DM. In this study, orally administered linagliptin, $5 \mathrm{mg}$ once daily, significantly improved 24-h glycemic control compared with placebo, as indicated by a reduction in plasma WMG levels. Twenty-four hours after the first dose of linagliptin, median DPP-4 inhibition was approximately $80 \%$, which has previously been proposed as the threshold for effective glycemic control [19]. Inhibition of DPP-4 was sustained throughout the 4 -week study, with a low level (17\%) detectable even 2 weeks after the end of linagliptin administration. These findings are consistent with stable binding of linagliptin to DPP-4 and the long terminal halflife of the drug $(128-184 \mathrm{~h}$ in healthy individuals) [14].
In accordance with these findings, linagliptin improved $\mathrm{HbA}_{1 \mathrm{c}}$ levels and longer-term markers of glycemic control, i.e., fructosamine and 1,5anhydroglucitol levels. The effect on $\mathrm{HbA}_{1 \mathrm{c}}$ was maintained 2 weeks after treatment cessation. As 1,5-anhydroglucitol competes with glucose for renal tubular reabsorption [20], it gives a better reflection of postmeal glycemic excursions than $\mathrm{HbA}_{1 \mathrm{c}}$ or fructosamine $[21,22]$. Indeed, in this study, linagliptin primarily reduced PPG levels rather than FPG; FPG was virtually unchanged $24 \mathrm{~h}$ after the first dose and moderately reduced (a decrease of approximately 6\% vs. baseline) after 4 weeks. In contrast, after 4 weeks of linagliptin administration, the change from baseline in plasma glucose $2 \mathrm{~h}$ after MTT (PPG) was $2.4 \mathrm{mmol} / \mathrm{L}$ (a decrease of approximately $15 \%)$. As the patients in this study had reasonably good glycemic control (mean baseline $\mathrm{HbA}_{1 \mathrm{c}}$ was $7.30 \pm 0.53 \%$ ), this may be a result of the glucose-dependent blood glucoselowering effect that has been observed with DPP4 inhibitors in general [3].

Medium-term markers of glycemic control might be more appropriate than $\mathrm{HbA}_{1 \mathrm{c}}$ to evaluate the potential of linagliptin to improve blood glucose control in a study with a 4-week treatment duration. Nevertheless, 
$\mathrm{HbA}_{1 \mathrm{c}}$ was included in the efficacy parameters following the recent findings of a significant effect of linagliptin on $\mathrm{HbA}_{1 \mathrm{c}}$ after 4 weeks of treatment [9]. The results presented here seem to be in accordance with previous studies; Nonaka et al. [23] reported a placebo-adjusted decrease in WMG of $1.4 \mathrm{mmol} / \mathrm{L}$ with sitagliptin $100 \mathrm{mg}$ in Japanese patients with T2DM. In a mostly non-Asian population of patients with T2DM with a slightly higher baseline $\mathrm{HbA}_{1 \mathrm{c}} \quad(7.7 \pm 0.8 \% ; \quad 57 \pm 0.7 \mathrm{mmol} /$ mol), 4 weeks of treatment with sitagliptin, added to a preexisting metformin therapy, resulted in a placebo-adjusted decrease in WMG of approximately $1 \mathrm{mmol} / \mathrm{L}$ [18]. $\mathrm{HbA}_{1 \mathrm{c}}$ was not reported in these studies in which sitagliptin was evaluated over a treatment period of 4 weeks; however, but the effect of sitagliptin on $\mathrm{HbA}_{1 \mathrm{c}}$ lowering in moderately controlled $\left(\mathrm{HbA}_{1 \mathrm{c}}<8 \% ; 64 \mathrm{mmol} / \mathrm{mol}\right)$ elderly patients over 12 weeks of treatment $(0.5 \%)$ [24] was not considerably greater than that observed with linagliptin over only 4 weeks in the present study $(0.3 \%)$. Therefore, the observed effect of linagliptin on $\mathrm{HbA}_{1 \mathrm{c}}$ seems to be within the range expected in patients with fairly well-controlled T2DM.

Inhibition of DPP-4 by linagliptin, and the resulting increases in GLP-1 levels, were accompanied by changes in GIP and other peptide hormones. The increased presence of intact GLP-1 in plasma was also associated with significant reductions in glucagon (peak excursion and AUEC $_{0-2 h}$ ) from day 1 of linagliptin administration. Furthermore, linagliptin produced significant reductions of approximately $15 \%$ in peak glucagon (data not shown) and approximately $10 \%$ in AUEC $_{0-2 h}$, on both days 1 and 28 .

It is well established that glucagon secretion exhibits characteristic abnormalities in T2DM. Frequently, patients have fasting hyperglucagonemia and exaggerated responses to meal tests [25]. GLP-1 is an inhibitor of glucagon secretion and also retains this ability in patients with T2DM [26]. It has recently been suggested that the clinical importance of the GLP-1-induced insulin stimulation and glucagon inhibition contribute equally to the glucose-lowering effect of GLP-1 in patients with T2DM [27]. Therefore, it is fair to assume that both the significant increase in GLP-1 and the decrease in glucagon levels accounted for the glucose-lowering potential of linagliptin in this study.

Importantly, GLP-1 elevation by DPP-4 inhibitors does not impair the counterregulatory response of glucagon to hypoglycemia [28]. Furthermore, linagliptin is associated with a negligible risk of hypoglycemia when administered as monotherapy. Indeed, no patient developed symptomatic hypoglycemia while receiving either of the DPP-4 inhibitors in this study, confirming the low risk observed in previous studies [6, 9, 14, 29-31].

The absence of any significant effects of linagliptin administration on insulin and C-peptide peak excursion or $\mathrm{AUEC}_{0-2 \mathrm{~h}}$ indicate that insulin levels are maintained despite a concomitant reduction in glucose levels. This suggests improved responsiveness of the pancreatic beta cells to glucose levels and an insulinotropic effect. It is important to note that GLP-1-mediated insulin secretion is glucosedependent and, as linagliptin reduced both the peak excursion and $\mathrm{AUEC}_{0-3 \mathrm{~h}}$ of glucose within 1 day, the interpretation of insulin and C-peptide data may need to take this into account. This presumably explains why no changes in insulin and C-peptide have been observed, and is in accordance with previous studies that did not find treatment-related changes in absolute fasting and postprandial insulin levels or in C-peptide levels [18, 32]. 
At present, there are no published head-tohead comparison studies between linagliptin and sitagliptin. Although this trial was not designed or sufficiently powered to compare the efficacy of these two drugs, exploratory analyses indicated no clinically or statistically significant differences in the efficacy of these two drugs, in terms of changes in 24-h WMG and intact GLP-1, or secondary endpoints, including FPG and glucose $\mathrm{AUEC}_{0-3 \mathrm{~h}}$, after 28 days of treatment. This finding is consistent with the authors' observation of a similar extent of DPP-4 inhibition by both linagliptin and sitagliptin. It is also consistent with current understanding of the mode of action of these two drugs, which, as a result of DPP-4 inhibition, produce sustained increases in GLP-1 levels, resulting in a lowering of plasma glucose levels.

The safety findings in this study indicate that linagliptin $5 \mathrm{mg}$ once daily was well tolerated, with an adverse event rate that was not higher than that observed with placebo. Overall, linagliptin and sitagliptin showed similar efficacy and tolerability.

\section{CONCLUSION}

In summary, the findings of this study show that linagliptin has a rapid onset of action in patients with T2DM, producing potent inhibition of DPP-4. This results in immediate and sustained increases in both intact GLP-1 and GIP. Most importantly, it results in statistically significant and clinically meaningful improvements in glycemic control that are similar to those previously reported for other DPP-4 inhibitors administered for a 4-week treatment period. Linagliptin treatment was well tolerated, did not cause hypoglycemia, and had an adverse event rate that was similar to both placebo and sitagliptin. Overall, linagliptin has shown similar efficacy and tolerability compared with other DPP-4 inhibitors. However, in contrast to other agents of its class, linagliptin is mainly eliminated unchanged via the bile and the gut, with little reliance on renal excretion; consequently, it does not require dose adjustment in patients with, or at risk of, declining renal function.

\section{ACKNOWLEDGMENTS}

The authors were fully responsible for all content and editorial decisions, were involved at all stages of manuscript development, and have approved the final version. The article publication charges were funded by Boehringer Ingelheim. The authors would like to acknowledge the contribution of Benjamin Lang of Boehringer Ingelheim to the development of the manuscript. Medical writing assistance, supported financially by Boehringer Ingelheim, was provided by Mark Greener and Stephanie Milsom of PHASE II International and Jennifer Edwards of Envision Scientific Solutions during the preparation of this article. Dr Rauch is the guarantor for this article, and takes responsibility for the integrity of the work as a whole.

Conflict of interest. T. Rauch, U. GraefeMody, H.-J. Woerle, and K. A. Dugi are employees of Boehringer Ingelheim, the sponsor of the study. A. Ring was an employee of Boehringer Ingelheim at the time when the study was performed and evaluated. C. F. Deacon has received consultancy/speaker fees from companies with an interest in developing and marketing incretin-based treatment for T2DM (Bristol Myers Squibb, Boehringer Ingelheim, Lilly, Merck, Novartis, Novo Nordisk). J. J. Holst has received consultancy/ lecture fees from Bristol Myers Squibb, 
GlaxoSmithKline, Merck Sharpe \& Dohme, Novartis, Novo Nordisk, and Roche. T. Heise is a shareholder of a private research institute that has received research grants from the following pharmaceutical companies in the past 12 months: Becton-Dickinson, Biodel, Boehringer Ingelheim, Eli Lilly, F. Hoffmann-La Roche Ltd., GlaxoSmithKline, Lundbeck, Merck Sharp \& Dohme, Novo Nordisk, Roche Diagnostics, Sanofi, and Servier. In addition, T. Heise has received travel grants, consulting fees, and speaker honoraria from Novo Nordisk and Boehringer Ingelheim.

Open Access. This article is distributed under the terms of the Creative Commons Attribution Noncommercial License which permits any noncommercial use, distribution, and reproduction in any medium, provided the original author(s) and the source are credited.

\section{REFERENCES}

1. Drucker DJ, Nauck MA. The incretin system: glucagon-like peptide-1 receptor agonists and dipeptidyl peptidase- 4 inhibitors in type 2 diabetes. Lancet. 2006;368:1696-705.

2. Holst JJ, Deacon CF. Inhibition of the activity of dipeptidyl-peptidase IV as a treatment for type 2 diabetes. Diabetes. 1998;47:1663-70.

3. Bohannon N. Overview of the gliptin class (dipeptidyl peptidase-4 inhibitors) in clinical practice. Postgrad Med. 2009;121:40-5.

4. Derosa G, Maffioli P. Dipeptidyl peptidase-4 inhibitors: 3 years of experience. Diabetes Technol Ther. 2012;14:350-64.

5. Deacon CF, Holst JJ. Linagliptin, a xanthine-based dipeptidyl peptidase- 4 inhibitor with an unusual profile for the treatment of type 2 diabetes. Expert Opin Investig Drugs. 2010;19:133-40.

6. Forst T, Uhlig-Laske B, Ring A, et al. Linagliptin (BI 1356), a potent and selective DPP-4 inhibitor, is safe and efficacious in combination with metformin in patients with inadequately controlled type 2 diabetes. Diabet Med. 2010;27:1409-19.
7. Scheen AJ. Pharmacokinetics of dipeptidylpeptidase-4 inhibitors. Diabetes Obes Metab. 2010;12:648-58.

8. Graefe-Mody U, Friedrich C, Port A, et al. Effect of renal impairment on the pharmacokinetics of the dipeptidyl peptidase-4 inhibitor linagliptin $\left(^{*}\right)$. Diabetes Obes Metab. 2011;13:939-46.

9. Forst T, Uhlig-Laske B, Ring A, Ritzhaupt A, GraefeMody U, Dugi KA. The oral DPP-4 inhibitor linagliptin significantly lowers $\mathrm{HbA}_{1 \mathrm{c}}$ after 4 weeks of treatment in patients with type 2 diabetes mellitus. Diabetes Obes Metab. 2011;13:542-50.

10. Gomis R, Espadero RM, Jones R, Woerle HJ, Dugi KA. Efficacy and safety of initial combination therapy with linagliptin and pioglitazone in patients with inadequately controlled type 2 diabetes: a randomized, double-blind, placebocontrolled study. Diabetes Obes Metab. 2011;13: 653-61.

11. Owens DR, Swallow R, Dugi KA, Woerle HJ. Efficacy and safety of linagliptin in persons with type 2 diabetes inadequately controlled by a combination of metformin and sulphonylurea: a 24-week randomized study. Diabet Med. 2011;28:1352-61.

12. Gallwitz B, Rosenstock J, Rauch T, et al. 2-year efficacy and safety of linagliptin compared with glimepiride in patients with type 2 diabetes inadequately controlled on metformin: a randomised, double-blind, non-inferiority trial. Lancet. 2012;380:475-83.

13. Heise T, Graefe-Mody EU, Huttner S, Ring A, Trommeshauser D, Dugi KA. Pharmacokinetics, pharmacodynamics and tolerability of multiple oral doses of linagliptin, a dipeptidyl peptidase-4 inhibitor in male type 2 diabetes patients. Diabetes Obes Metab. 2009;11:786-94.

14. Hüttner S, Graefe-Mody EU, Withopf B, Ring A, Dugi KA. Safety, tolerability, pharmacokinetics, and pharmacodynamics of single oral doses of BI 1356, an inhibitor of dipeptidyl peptidase 4 , in healthy male volunteers. J Clin Pharmacol. 2008;48:1171-8.

15. Deacon CF, Nauck MA, Meier J, Hücking K, Holst JJ. Degradation of endogenous and exogenous gastric inhibitory polypeptide in healthy and in type 2 diabetic subjects as revealed using a new assay for the intact peptide. J Clin Endocrinol Metab. 2000;85:3575-81.

16. Hoelzel W, Weykamp C, Jeppsson JO, IFCC Working Group on HbA1c Standardization, et al. IFCC reference system for measurement of hemoglobin $\mathrm{A}_{1 \mathrm{c}}$ in human blood and the national standardization schemes in the United States, Japan, and Sweden: a method-comparison study. Clin Chem. 2004;50:166-74. 
17. Sacks DB. Global harmonization of hemoglobin A 1 . Clin Chem. 2005;51:681-3.

18. Brazg R, Xu L, Dalla Man C, Cobelli C, Thomas K, Stein PP. Effect of adding sitagliptin, a dipeptidyl peptidase-4 inhibitor, to metformin on $24-\mathrm{h}$ glycaemic control and beta-cell function in patients with type 2 diabetes. Diabetes Obes Metab. 2007;9:186-193.

19. Roy RS, Wu J, Eiermann G, et al. Plasma DPP-4 inhibition by sitagliptin and other DPP-4 inhibitors correlates with and predicts glucose lowering efficacy. Diabetes. 2009;58:A612.

20. Yamanouchi $T$, Moromizato $H$, Shinohara $T$, Minoda S, Miyashita H, Akaoka I. Estimation of plasma glucose fluctuation with a combination test of hemoglobin $A_{1 c}$ and 1,5-anhydroglucitol. Metabolism. 1992;41:862-7.

21. Dungan KM, Buse JB, Largay J, et al. 1,5anhydroglucitol and postprandial hyperglycemia as measured by continuous glucose monitoring system in moderately controlled patients with diabetes. Diabetes Care. 2006;29:1214-9.

22. Stettler C, Stahl M, Allemann S, et al. Association of 1,5-anhydroglucitol and 2-h postprandial blood glucose in type 2 diabetic patients. Diabetes Care. 2008;31:1534-5.

23. Nonaka K, Tsubouchi H, Okuyama K, Fukao Y, Johnson-Levonas AO, Amatruda JM. Effects of once-daily sitagliptin on 24-h glucose control following 4 weeks of treatment in Japanese patients with type 2 diabetes mellitus. Horm Metab Res. 2009;41:232-7.

24. Barzilai N, Guo H, Mahoney EM, et al. Efficacy and tolerability of sitagliptin monotherapy in elderly patients with type 2 diabetes: a randomized, double-blind, placebo-controlled trial. Curr Med Res Opin. 2011;27:1049-58.
25. Toft-Nielsen MB, Damholt MB, Madsbad S, et al. Determinants of the impaired secretion of glucagon-like peptide- 1 in type 2 diabetic patients. J Clin Endocrinol Metab. 2001;86:3717-23.

26. Vilsboll T, Krarup T, Madsbad S, Holst JJ. Defective amplification of the late phase insulin response to glucose by GIP in obese Type II diabetic patients. Diabetologia. 2002;45:1111-9.

27. Hare KJ, Vilsboll T, Asmar M, Deacon CF, Knop FK, Holst JJ. The glucagonostatic and insulinotropic effects of glucagon-like peptide 1 contribute equally to its glucose-lowering action. Diabetes. 2010;59: 1765-70.

28. Ahrén B, Schweizer A, Dejager S, et al. Vildagliptin enhances islet responsiveness to both hyper- and hypoglycemia in patients with type 2 diabetes. J Clin Endocrinol Metab. 2009;94:1236-43.

29. Del Prato S, Barnett AH, Huisman H, Neubacher D, Woerle HJ, Dugi KA. Effect of linagliptin monotherapy on glycaemic control and markers of beta-cell function in patients with inadequately controlled type 2 diabetes: a randomized controlled trial. Diabetes Obes Metab. 2011;13:258-67.

30. Karasik A, Aschner P, Katzeff H, Davies MJ, Stein PP. Sitagliptin, a DPP-4 inhibitor for the treatment of patients with type 2 diabetes: a review of recent clinical trials. Curr Med Res Opin. 2008;24:489-96.

31. Taskinen MR, Rosenstock J, Tamminen I, et al. Safety and efficacy of linagliptin as add-on therapy to metformin in patients with type 2 diabetes: a randomized, double-blind, placebo-controlled study. Diabetes Obes Metab. 2011;13:65-74.

32. Ahrén B, Simonsson E, Larsson H, et al. Inhibition of dipeptidyl peptidase IV improves metabolic control over a 4 -week study period in type 2 diabetes. Diabetes Care. 2002;25:869-75. 